\title{
Response of the Mediterranean mean sea level to atmospheric pressure forcing
}

\author{
Pierre-Yves Le Traon and Philippe Gauzelin \\ Direction Océanographie Spatiale, Collecte Localisation Satellites, Toulouse, France
}

\begin{abstract}
The response of the Mediterranean mean sea level to atmospheric pressure forcing is analyzed using 3 years of TOPEX/POSEIDON data. Coherence analysis between mean sea level and atmospheric pressure shows a significant departure from a standard inverse barometer effect at frequencies higher than 30 days $^{-1}$. At high frequencies the phase difference between sea level and pressure is about $100^{\circ}$, while it should be $180^{\circ}$ for a perfect inverse barometer response. This result is in agreement with previous findings and confirms the role of the Straits of Gibraltar and Sicily in limiting the water exchange (and thus the response to atmospheric pressure forcing) at high frequencies. The response of the Mediterranean mean sea level is then investigated using the Candela [1991] analytical model which takes account of friction in the Straits of Gibraltar and Sicily. The model explains a large part of the variance in TOPEX/POSEIDON mean sea level variations ( $50 \%$ for the western basin and $38 \%$ for the eastern basin). Compared to an inverse barometer correction, it gives a smoother response with a phase delay at high frequencies. It also explains more variance in TOPEX/POSEIDON mean sea level variations $\left(5 \mathrm{~cm}^{2}\right.$ and $7 \mathrm{~cm}^{2}$ for the western and eastern basins, respectively). This demonstrates that this simple model provides an improved correction of atmospheric pressure effects in TOPEX/POSEIDON data. As the two corrections have an rms difference of $2-3 \mathrm{~cm}$ with maximum differences of up to 10 $\mathrm{cm}$, the impact on the mapping of oceanic circulation is not negligible. This is exemplified through the comparison of sea level anomaly derived from the two corrections.
\end{abstract}

\section{Introduction}

In the open ocean the response of sea level to atmospheric pressure is close to the well-known inverse barometer (IB) effect [e.g., Wunsch, 1972; Ponte, 1993; Fu and Pihos, 1994; Gaspar and Ponte, 1996]. The IB correction (IBC) (to be subtracted to the sea surface height) is simply given by

$$
\mathrm{IBC}=-1 / \rho g\left(P-P_{\mathrm{ref}}\right)
$$

where $P_{\text {ref }}$ is the mean pressure over the ocean which, in practice, is often assumed to be constant ( $\rho$ is density, $g$ is gravity). A 1-mbar increase in atmospheric pressure thus induces a sea level depression of about $1 \mathrm{~cm}$.

In a closed basin, because mass must be conserved, $P_{\text {ref }}$ must be made equal to the mean pressure over the basin; the mean sea level does not thus respond to the mean pressure, and only adjustments of sea level to pressure anomalies (e.g., due to spatial variations of pressure) are possible. In a semi-enclosed sea such as the Mediterranean the response is more complex. The sea level can respond to the mean pressure over the basin if there is an adjustment through the straits. From the work of Lacombe [1961] and Crepon [1965] it has been recognized that this adjustment occurs. Crepon [1965] observed a correlation between the flux through the Strait of Gibraltar and the mean atmospheric pressure. Actually, the continuity equation would imply a correlation with the time derivative of pressure, not pressure itself. Several papers have dealt with the problem [e.g., Garrett, 1983; Garrett and Majaess, 1984]. Candela et al.

Copyright 1997 by the American Geophysical Union.

Paper number 96JC02777.

0148-0227/97/96JC-02777\$09.00
[1989] and Candela [1991] have proposed a simple analytical model which takes account of the friction in the Straits of Gibraltar and Sicily. The model provides a response of sea level to a given spectrum of atmospheric pressure. At low frequencies the straits do not constrain the flow. At high frequencies the Mediterranean cannot fully adjust, and the response differs significantly from a standard IB effect. As a consequence, perfect correlation with pressure changes cannot be expected which partly solved the contradiction. This model was tested with tide gauges and explained a large part of the sea level variance signal [Candela, 1991].

The nonisostatic response of sea level to atmospheric pressure forcing in the Mediterranean Sea has been observed from the analysis of tide gauge data. The response is mainly underisostatic at high frequencies and overisostatic at low frequencies [Lascaratos and Gacic, 1990; Tsimplis and Mahakis, 1994]. Tide gauges give the sea level response at a given place. This local response will be different, however, from the basin average response. It will include, in particular, the effect of wind which is unlikely for the mean sea level response [e.g., Garrett, 1983].

Thanks to the high accuracy of TOPEX/POSEIDON (hereafter T/P) data, satellite altimetry can now be used to quantitatively measure the mean sea level (and oceanic circulation variations) in the Mediterranean Sea [Larnicol et al., 1995]. T/P provides global coverage of the Mediterranean which should improve analysis of mean sea level variations and in particular of the influence of atmospheric pressure. In addition, to analyze other signals such as oceanic circulation variations, it is important to correct altimetric data for atmospheric pressure effects. In their analysis of T/P data in the Mediterranean Sea, 


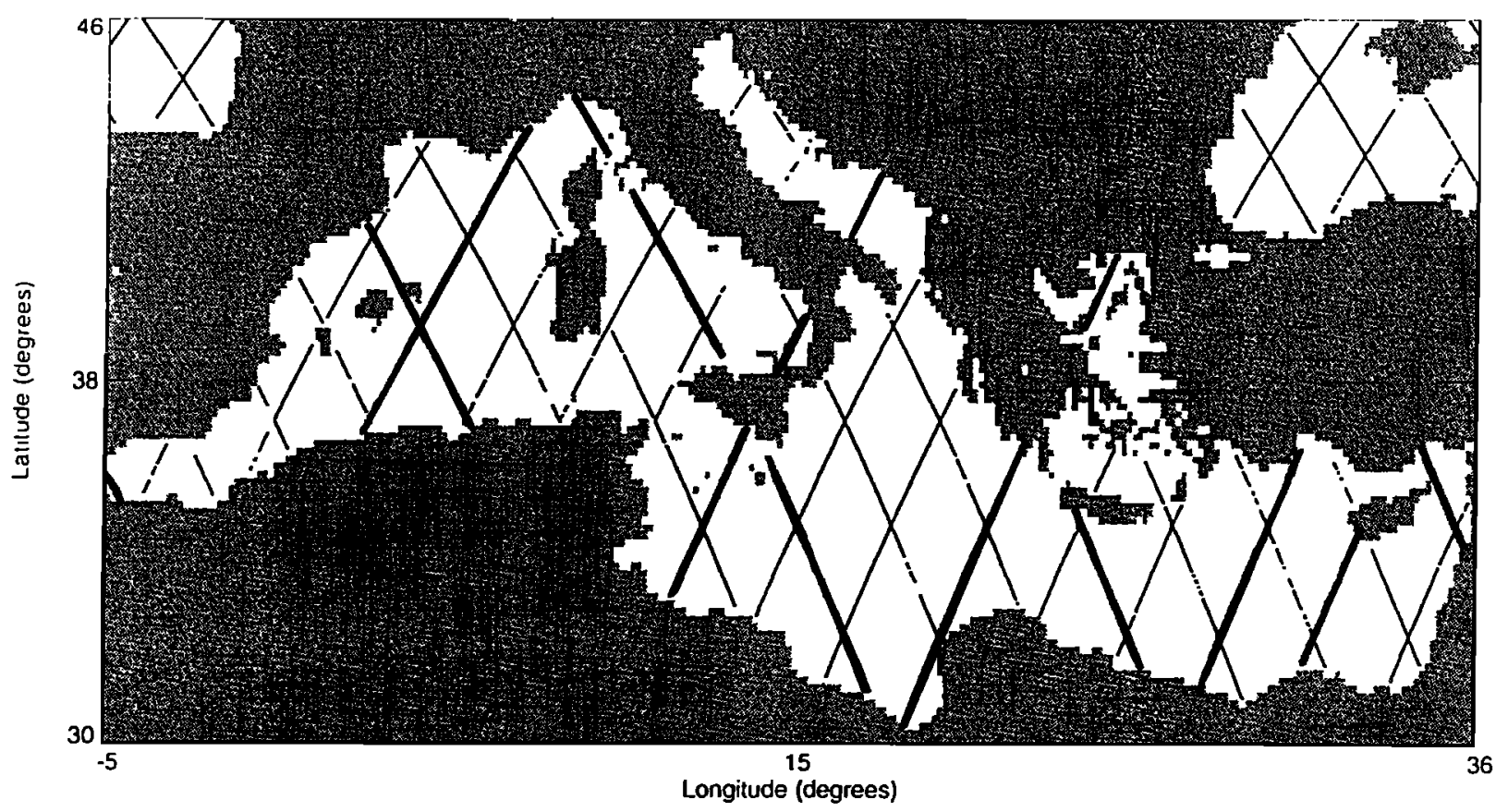

Figure 1. Location of TOPEX/POSEIDON tracks in the Mediterranean Sea. Tracks in bold are sampled during the first 3 days of the cycle.

Larnicol et al. [1995] found a mean response of sea level to atmospheric pressure close to an inverse barometer effect. However, the sea level variations corrected for an IB effect still showed high-frequency $\left(<(10 \text { days })^{-1}\right)$ large-scale variations. They suggested that this may result from an inaccurate correction of atmospheric pressure effect at high frequencies.

This study aims at better understanding the atmospheric pressure effect on the Mediterranean mean sea level. Another objective is to provide a more precise correction of this effect in altimetric data. We will use 3 years of highly precise T/P data and European Centre for Medium-Range Weather Forecast (ECMWF) atmospheric pressure data. The paper is organized as follows. Data and processing are detailed in section 2. Section 3 deals with a coherence analysis between $T / P$ mean sea level and atmospheric pressure. Implementation and use of the Candela [1991] analytical model are presented in section 4. This includes the comparison with the standard inverse barometer effect. Conclusions and prospects are given in section 5 .

\section{Data and Processing}

\subsection{TOPEX/POSEIDON Data}

T/P merged geophysical data records (M-GDRs) [Archiving, Validation, and Interpretation of Satellite Data in Oceanography (AVISO), 1992] from the first 3 years were used for this study (Figure 1). The records span the period between October 24, 1992 (cycle 4), and October 18, 1995 (cycle 113), i.e., a total of 110 ten-day cycles (the first three T/P cycles are not used, because of spacecraft pointing problems). The Joint Gravity Model (JGM-3) precise orbit and the following corrections [see Le Traon et al., 1994] were used: the TOPEX microwave radiometer (TMR) for the wet troposphere, ECMWF for the dry troposphere, 300-km low-pass-filtered bifrequency ionospheric correction for TOPEX, Doppler orbitography and radiopositioning integrated by satellite (DORIS) ionospheric correction for POSEIDON, electromagnetic bias correction using the BM4 parameterization for both instruments [Gaspar et al., 1994], Cartwright and Tayler [1971] solid tides, Ray and Sanchez [1989] tidal loading, and P. Canceill et al. (Barotropic tides in the Mediterranean Sea using a finite element numerical model, submitted to Journal of Geophysical Research, 1996) ocean tides. Along-track corrected sea surface heights were resampled every $7 \mathrm{~km}$ using cubic splines, and sea level anomaly (SLA) measurements were obtained by removing the 3-year mean. To reduce altimetric noise, SLA data were lowpass filtered using a $35-\mathrm{km}$ median filter and a Lanczos filter with a cutoff wavelength of $42 \mathrm{~km}$.

As one of the objectives of the study is to analyze the highfrequency response of the Mediterranean mean sea level to atmospheric pressure forcing, it was necessary to generate a time series of the mean sea level. T/P provides a complete sampling of the Mediterranean Sea every 10 days. However, since sea level variations induced by atmospheric pressure are basin scale, better temporal sampling can be achieved. We chose to generate time series with a time sampling of 1.25 days ( $1 / 8$ cycle). Note that the adjustment timescale of the Mediterranean Sea to atmospheric pressure forcing is below 1 day, as gravity waves take a few hours to cross the Mediterranean basin. Typically, 2 or 3 tracks can be obtained in a window of 1.25 days. Data are then smoothed over time, taking a smoothing window of \pm 2 days and an exponential weighting with a time decay of 1 day. We thus assume that the mean sea level derived from these tracks is representative of the real mean sea level. This is probably a valid assumption although other oceanic signals (e.g., due to oceanic circulation variations) are less well averaged at high frequencies. Thus, although our time sampling theoretically allows us to study the mean sea level variations up to periods of 2.5 days, the noise due to other oceanic signals (and the smoothing applied to the data) probably does not allow us to analyze the very high frequency mean sea level variations.

The mean sea level derived from the 3 years is shown in 


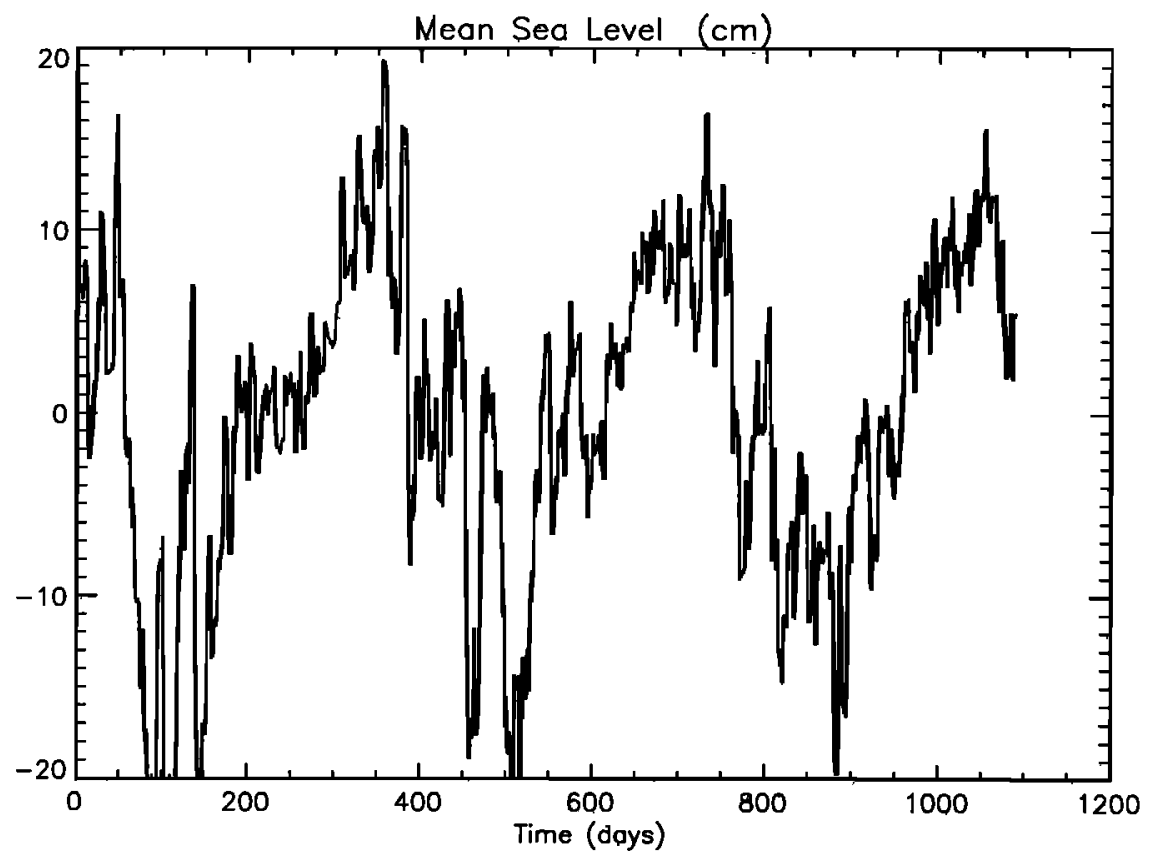

Figure 2. Mean sea level variations (in centimeters) in the Mediterranean Sea uncorrected for atmospheric pressure effects from October 1992 to October 1995.

Figure 2. The variance of mean sea level is $75 \mathrm{~cm}^{2}$ and is dominated by the seasonal signal. For frequencies higher than 50 days $^{-1}$ the variance is $14 \mathrm{~cm}^{2}$. As will be shown later, high-frequency variations are mainly due to atmospheric pressure forcing. At longer timescales and in particular at the seasonal timescale, other effects become more important (e.g., steric effect due to heat fluxes, variation in inflow and outflow). These are discussed by Larnicol et al. [1995].

\subsection{Atmospheric Pressure}

Atmospheric pressure data are derived from ECMWF model analyses. The model is spectral, and outputs are provided on a grid with a resolution of $0.5^{\circ}$ by $0.5^{\circ}$ every 6 hours. The mean atmospheric pressure variations (relative to the mean) over the Mediterranean Sea over the 3 years are shown in Figure 3. There are large variations in mean pressure (up to

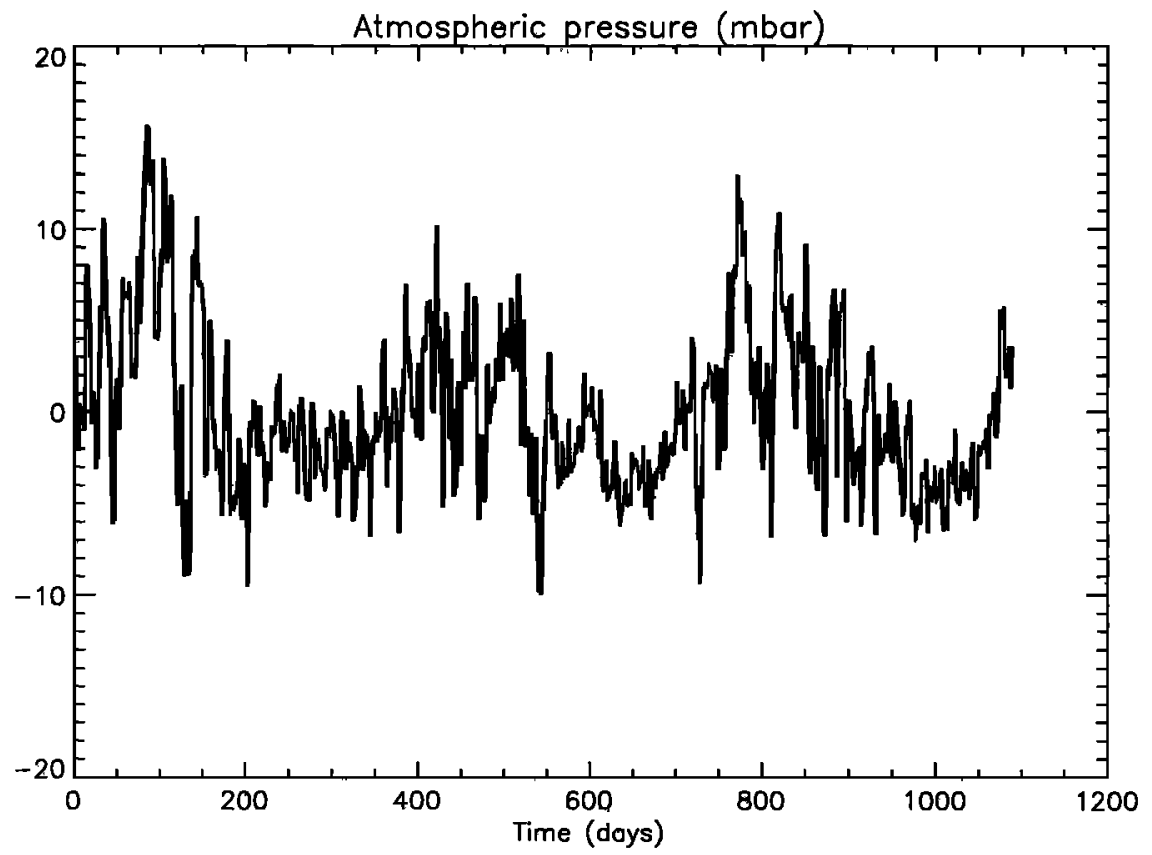

Figure 3. Mean atmospheric pressure variations (in millibars) in the Mediterranean Sea from October 1992 to October 1995. 

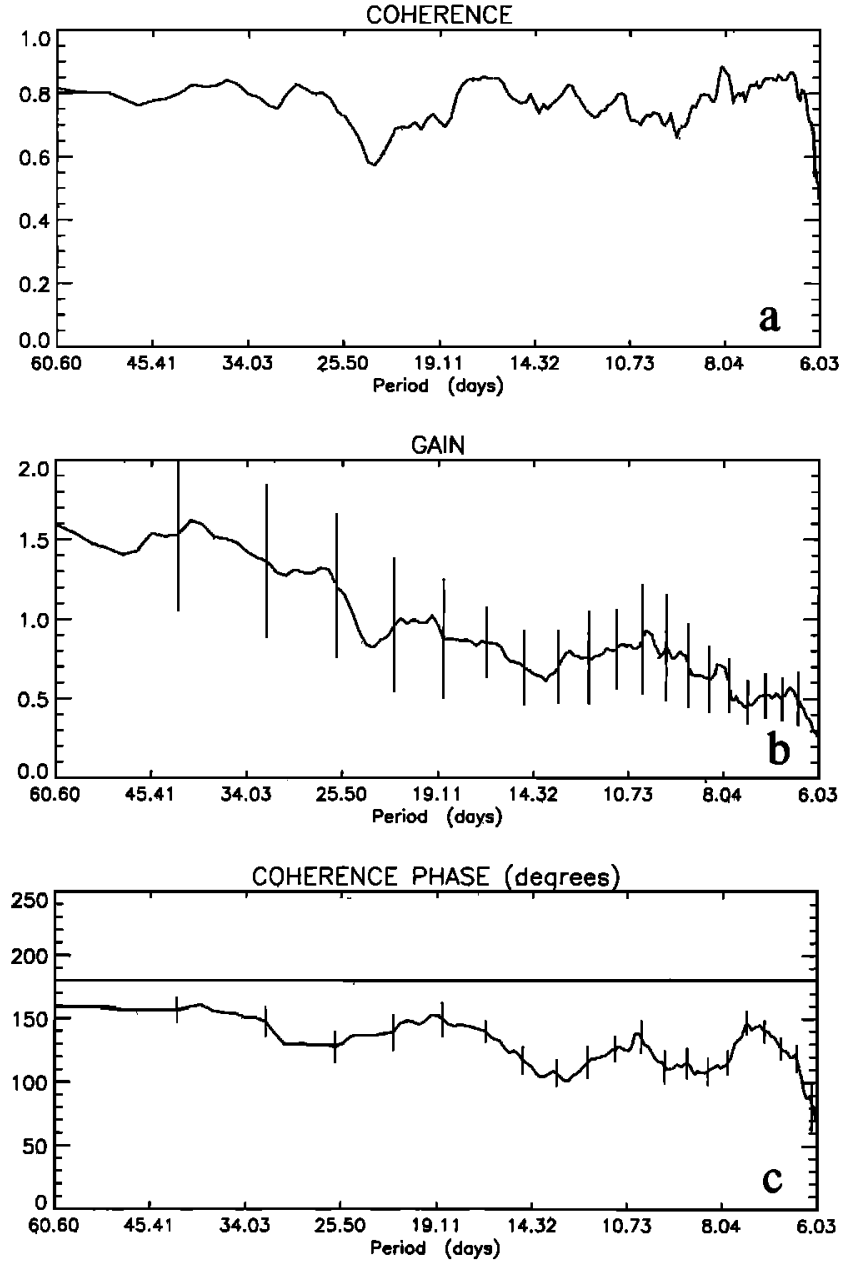

Figure 4. (a) Coherence, (b) gain, and (c) phase between mean sea level and atmospheric pressure for the Mediterranean Sea.

\pm 15 mbar) at high frequencies, especially during winter. There is also a seasonal signal, winter being on average more anticyclonic. The variance of mean pressure is $19 \mathrm{mbar}^{2}$, about a quarter that of mean sea level (assuming millibars match centimeters). This mainly reflects the smaller seasonal signal of the atmospheric pressure. For frequencies higher than (50 days $)^{-1}$ the variance is $8 \mathrm{mbar}^{2}\left(14 \mathrm{~cm}^{2}\right.$ for mean sea level), and for frequencies higher than ( 25 days) $)^{-1}$ the atmospheric pressure and mean sea level have almost the same variance.

Atmospheric ECMWF pressure data are already interpolated along T/P tracks. These could be used to generate time series of "along-track" pressure data following the same method as for sea level (see above). To better estimate the mean pressure, it is preferable, however, to directly use ECMWF gridded data. The time series of atmospheric pressure was thus derived from the gridded ECMWF pressure data. The same processing as for T/P sea level data was applied; that is, data were averaged over 1.25 days and smoothed with an exponential function. This removes, of course, part of the highfrequency signal. The difference in variance between the unfiltered and filtered atmospheric pressure time series is about 3 mbar $^{2}$.

\section{Coherence Analysis}

Coherence analysis between the mean sea level and atmospheric pressure time series provides a means to observe the frequency dependent response of sea level to atmospheric pressure [e.g., Bendat and Piersol, 1986]. Coherence, gain, and phase between mean sea level and mean atmospheric pressure are shown in Figures $4 a, 4 b$, and $4 c$, respectively. Smoothing was done over 20 adjacent frequencies and error bars were calculated [Bendat and Piersol, 1986]. Ninety-five percent confidence interval for a 0.8 coherence is thus \pm 0.15 . Results are shown for frequencies between $(60 \text { days })^{-1}$ and $(6 \text { days })^{-1}$ because pressure is the dominant signal only for intraseasonal frequencies and because results at frequencies higher than (6 days) $)^{-1}$ were shown to be sensitive to the T/P coverage and to the smoothing applied to the pressure and sea level data.

The coherence is fairly high, on average close to 0.8 , although it drops to 0.6 at periods between 20 and 30 days for an unexplained reason. The phase difference is always below $180^{\circ}$, the phase of a perfect inverse barometer effect. It decreases with frequency, and at frequencies higher than (15 days) $)^{-1}$ it is about $100^{\circ}$. At frequencies higher than (10 days $)^{-1}$ the gain is smaller than 1 which means that the response is also reduced in amplitude. There is thus a significant departure from an inverse barometer effect at high frequencies. The low values of
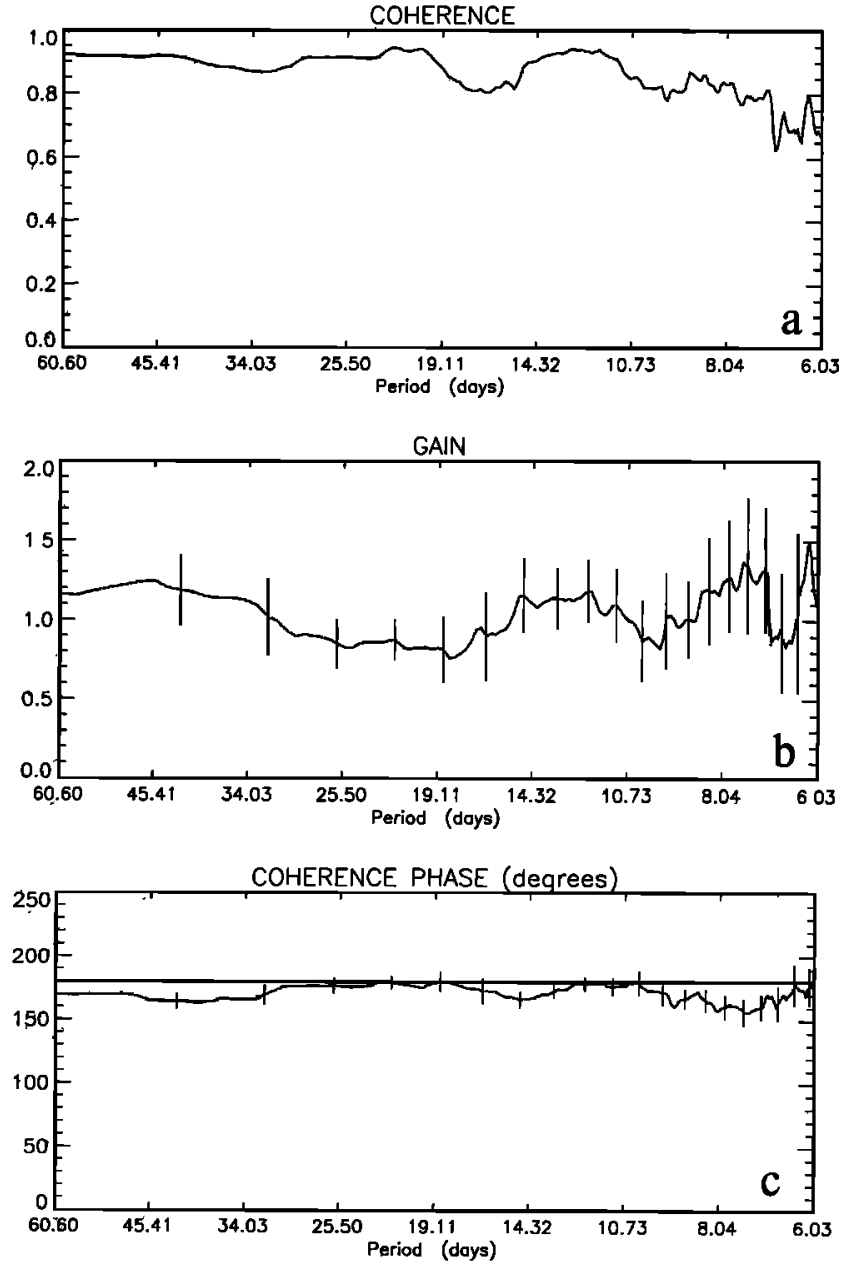

Figure 5. (a) Coherence, (b) gain, and (c) phase between mean sea level and atmospheric pressure for the Atlantic near the Strait of Gibraltar. 
phase correspond to a delay in the response of the sea level. This result is in agreement with previous findings [e.g., Crepon, 1965] of correlation of flux at Gibraltar with pressure rather than with time derivative of pressure. The flux at Gibraltar is, indeed, proportional to the time derivative of sea level. A correlation of this flux with pressure would thus imply a $90^{\circ}$ phase difference between sea level and pressure. This is approximately the value we find at high frequencies.

The gain is also larger than 1 at frequencies lower than (25 days $)^{-1}$. This is in agreement with previous results based on coastal data [e.g., Tsimplis and Vlahakis, 1994] although results here deal with the basin average response. This is probably related to other signals which can be correlated with atmospheric pressure (e.g., steric effect, wind). Part of this could also be explained by an underestimation of the ECMWF mean pressure variations [e.g., Gaspar and Ponte, 1996]. A comparison with mean pressure calculated with in situ data (a set of more than 60 coastal stations) has been performed for this study. It did not show, however, any significant underestimation of the ECMWF mean pressure variations.

For comparison purposes the same calculation was performed in an Atlantic box of $10^{\circ}$ in latitude by $15^{\circ}$ in longitude near the Strait of Gibraltar (Figure 5). The coherence is higher and the gain is not significantly different from 1 . The phase difference is also very close to $180^{\circ}$. This confirms that significant and specific departures from an inverse barometer effect in the Mediterranean Sea are well evidenced by $\mathbf{T} / \mathbf{P}$ data.

\section{Modeling the Response With the Candela Model}

\subsection{The Candela Model}

The Candela [1991] model is used to analyze how the Mediterranean mean sea level responds to atmospheric pressure forcing. The model is described in detail by Candela [1991], and only the main features are given here. The model provides the response of mean sea level in the western and eastern basins given atmospheric pressure forcing. At the Straits of Gibraltar and Sicily it assumes a balance between acceleration, along-strait pressure gradient, and friction. This yields the following set of equations:

$$
\begin{gathered}
A_{W} \frac{\partial \eta_{1}}{\partial t}=Q_{1}-Q_{2} \quad A_{E} \frac{\partial \eta_{2}}{\partial t}=Q_{2} \\
P_{1}=P_{a W}+\rho g \eta_{1} \quad P_{2}=P_{a E}+\rho g \eta_{2} \\
\frac{\partial Q_{1}}{\partial t}=-\frac{A_{G}}{\rho} \frac{\partial P}{\partial x}-\lambda_{1} Q_{1} \quad \frac{\partial Q_{2}}{\partial t}=-\frac{A_{S}}{\rho} \frac{\partial P}{\partial x}-\lambda_{2} Q_{2}
\end{gathered}
$$

where

$A_{E} \quad$ area of eastern basin $\left(1.6703 \times 10^{12} \mathrm{~m}^{2}\right)$;

$A_{W}$ area of western basin $\left(8.646 \times 10^{11} \mathrm{~m}^{2}\right)$;

$A_{G}$ section area of Strait of Gibraltar $\left(2.951 \times 10^{6} \mathrm{~m}^{2}\right)$;

$A_{S}$ section area of Strait of Sicily $\left(1.8926 \times 10^{7} \mathrm{~m}^{2}\right)$;

$P_{i}$ mean subsurface pressure for basin $i$;

$P_{a \imath}$ mean atmospheric pressure for basin $i$;

$\eta_{l}$ mean sea level for basin $i$;

$Q_{i}$ flux across strait $i$

$t$ time;

$x$ along-strait coordinate;

$\lambda_{i}$ friction coefficient for strait $i$.
Thus $\partial P / \partial x$ is thus equal to $\left(P_{2}-P_{1}\right) / L_{S}$ for the Strait of Sicily and $\left(P_{1}-P_{0}\right) / L_{G}$ for the Strait of Gibraltar. $L_{G}$ and $L_{S}$ are the lengths of the Straits of Gibraltar and Sicily. They are taken as $6.10^{4} \mathrm{~m}$ and $10^{5} \mathrm{~m}$ (geometric values). They should more likely correspond to dynamical lengths, but, as noted by Candela [1991], dynamical lengths should not differ from geometric lengths by more than the width of the straits.

There are six equations and seven unknowns $\left(\eta_{1}, \eta_{2}, P_{0}\right.$, $\left.P_{1}, P_{2}, Q_{1}, Q_{2}\right) . P_{0}$ is the subsurface pressure in the Atlantic just west of the Strait of Gibraltar. Candela [1991] assumes a constant $P_{0}$, i.e., that the response of sea level in the Atlantic is free to respond isostatically to atmospheric pressure forcing. This assumption makes sense and is corroborated by the coherence analysis shown on Figure 5. Still, the influence of a nonconstant $P_{0}$ will be investigated in section 4.5. If $P_{0}$ is set equal to zero (or is no longer considered as an unknown), one is left with six unknowns for six equations. This linear system can be solved for a given frequency taking each variable proportional to $e^{i \omega t}$. Coefficients relating the unknowns to the atmospheric pressure $P_{a W}$ and $P_{a E}$ are given by Candela [1991].

Note that if the friction coefficient in the Candela model is taken equal to $f W / L$ ( $f$ is the Coriolis parameter, $W$ is the width of straits, and $L$ is the length of straits), then the Candela model is equivalent to the Garrett [1983] model which uses geostrophic control at straits. For a ratio $W / L$ equal to 0.3 the Candela model with a friction of $3 \times 10^{-5}$ would thus be equivalent to the Garrett model.

\subsection{Application}

The application is straightforward. A Fourier transform is applied to the time series of mean pressure for the western and eastern basins. This yields their amplitude for a given frequency. The amplitudes of the unknowns (e.g., $\eta_{1}, \eta_{2}$ ) for this frequency are then derived from the relations given by the Candela model. The time series of the unknowns are finally obtained through an inverse Fourier transform. The model can be applied to filtered (sampling of 1.25 days) or nonfiltered (sampling of 6 hours) mean atmospheric pressure time series. In the following the filtered time series have been used to derive model results with the same sampling as $\mathrm{T} / \mathrm{P}$ mean sea levels. Nonfiltered mean atmospheric pressure will be used in section 4.4.

The values of the friction coefficients were adjusted to T/P data through the minimization of $\Sigma_{\text {time }}\left[\eta_{T / P}-\eta_{\text {Candela }}\right]^{2}$, where $\eta_{T / P}$ is the mean sea level measured by T/P and $\eta_{\text {Candela }}$ is the response given by the Candela model. Prior to this calculation the seasonal signal was removed (via a least squares fit) from the atmospheric pressure and sea level time series because the seasonal signal in sea level is clearly not dominated by atmospheric pressure effect. The minimization is done separately for the western and eastern basins. Figures $6 \mathrm{a}$ and $6 \mathrm{~b}$ show the variations of the rms difference between $T / P$ mean sea level and Candela model according to the different values of the two friction coefficients $\left(\lambda_{1}\right.$ and $\left.\lambda_{2}\right)$ for the western and eastern basins, respectively. The strong dependence on $\lambda_{1}$ demonstrates the role of friction in the Strait of Gibraltar. The dependence in the Strait of Sicily is much less marked as already noted by Candela et al. [1989]. Note, however, that these results may be sensitive to signals in T/P mean sea level which are not related to atmospheric pressure.

On the basis of these results, we estimated a friction coefficient $\lambda_{1}$ of $3.8 \times 10^{-5} \mathrm{~s}^{-1}$ for the Strait of Gibraltar. The same value was used for the Strait of Sicily friction $\lambda_{2}$ although the 


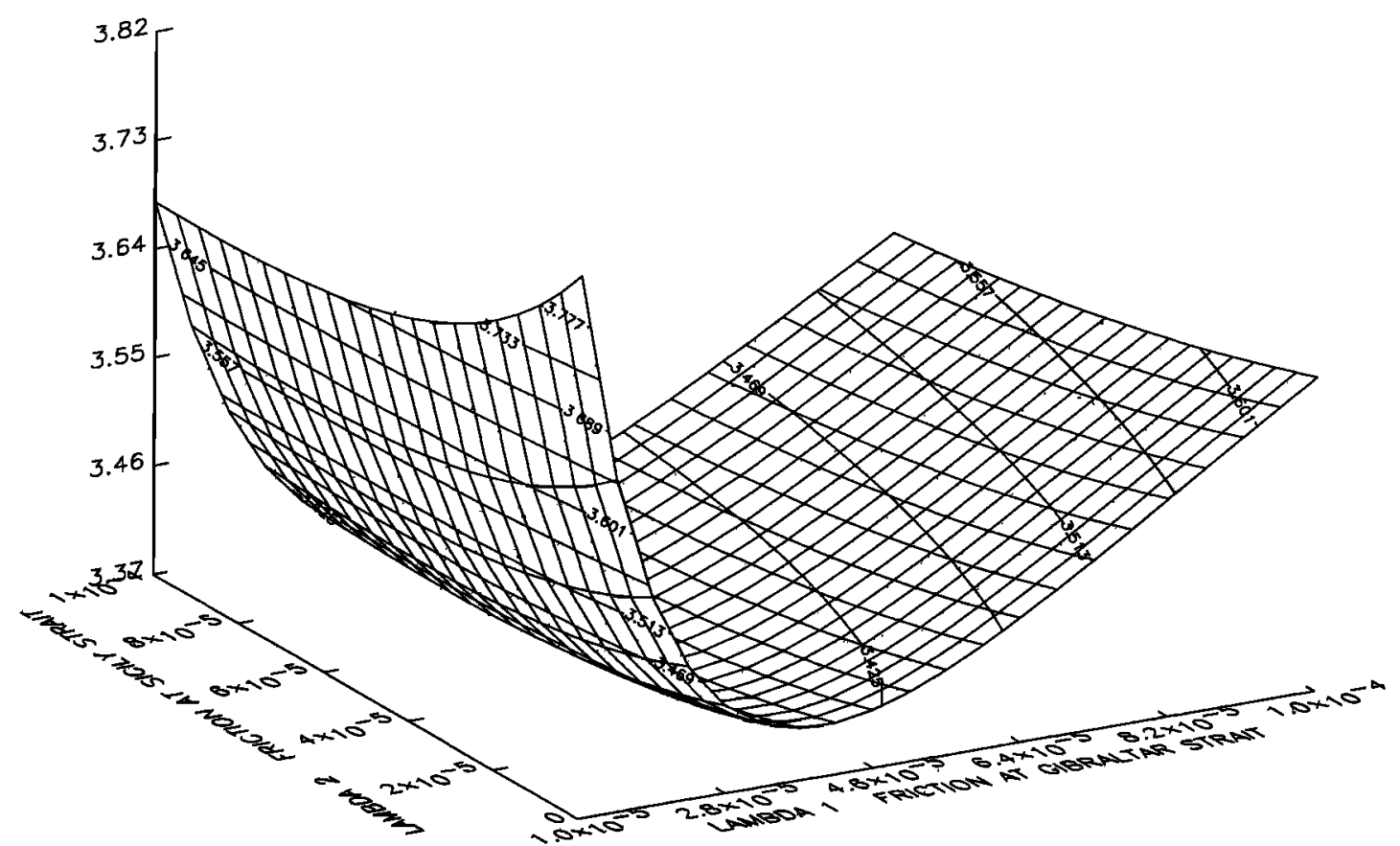

Figure 6a. Variation in the rms difference (in centimeters) between T/P mean sea level and Candela model in the western basin according to friction coefficients at the Straits of Gibraltar and Sicily.

results are not very sensitive to it. These values are very similar to that estimated by Candela [1991]: $4 \times 10^{-5} \mathrm{~s}^{-1}$ for both straits. As explained above, they are thus only slightly larger than the values corresponding to geostrophic control.

\subsection{Results}

Plate 1a presents sea level predicted by the model and a standard inverse barometer correction $(-1 / \rho g\langle P\rangle$, where $\langle P\rangle$

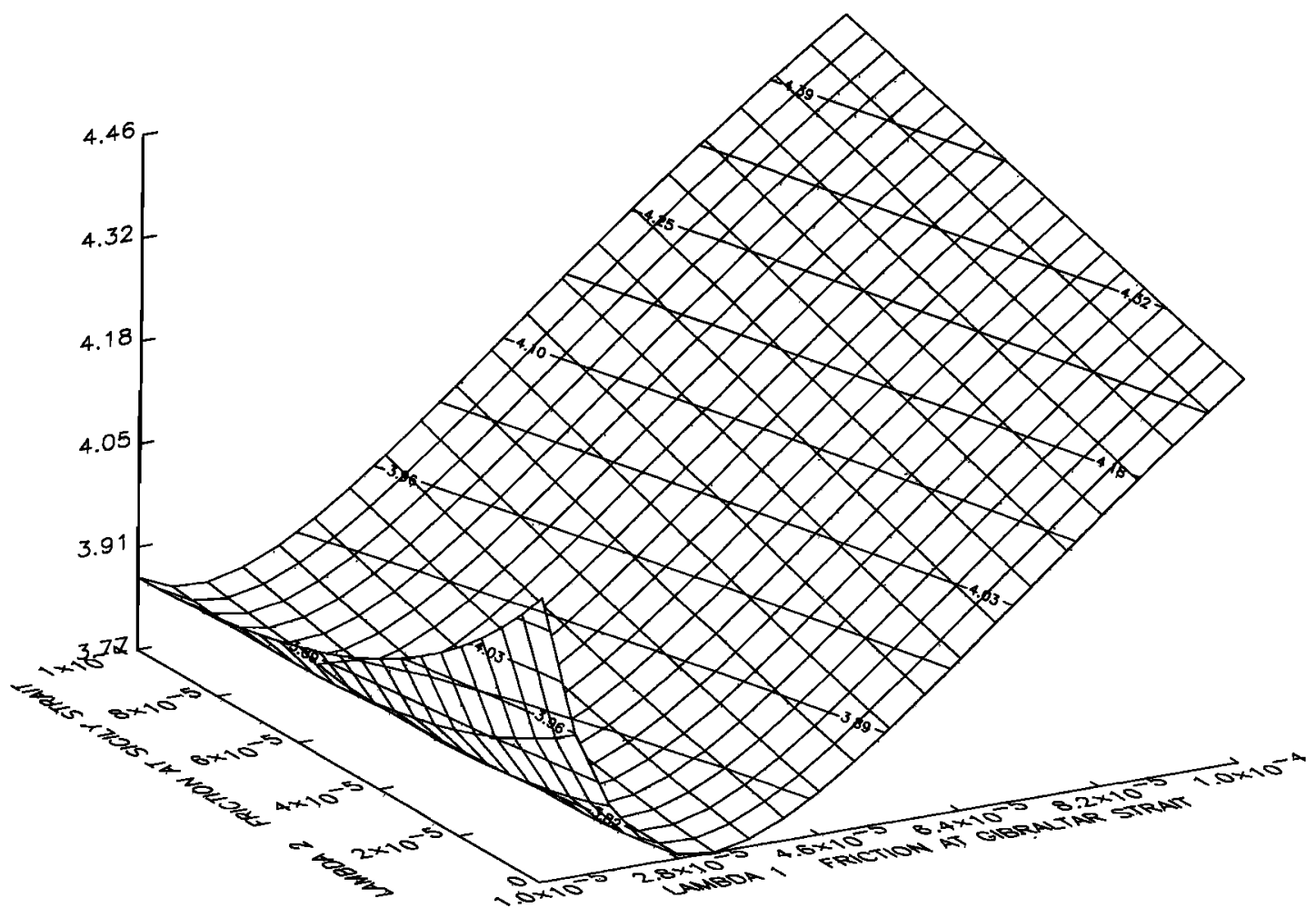

Figure 6b. Variation in the rms difference (in centimeters) between T/P mean sea level and Candela model in the eastern basin according to friction coefficients at the Straits of Gibraltar and Sicily. 

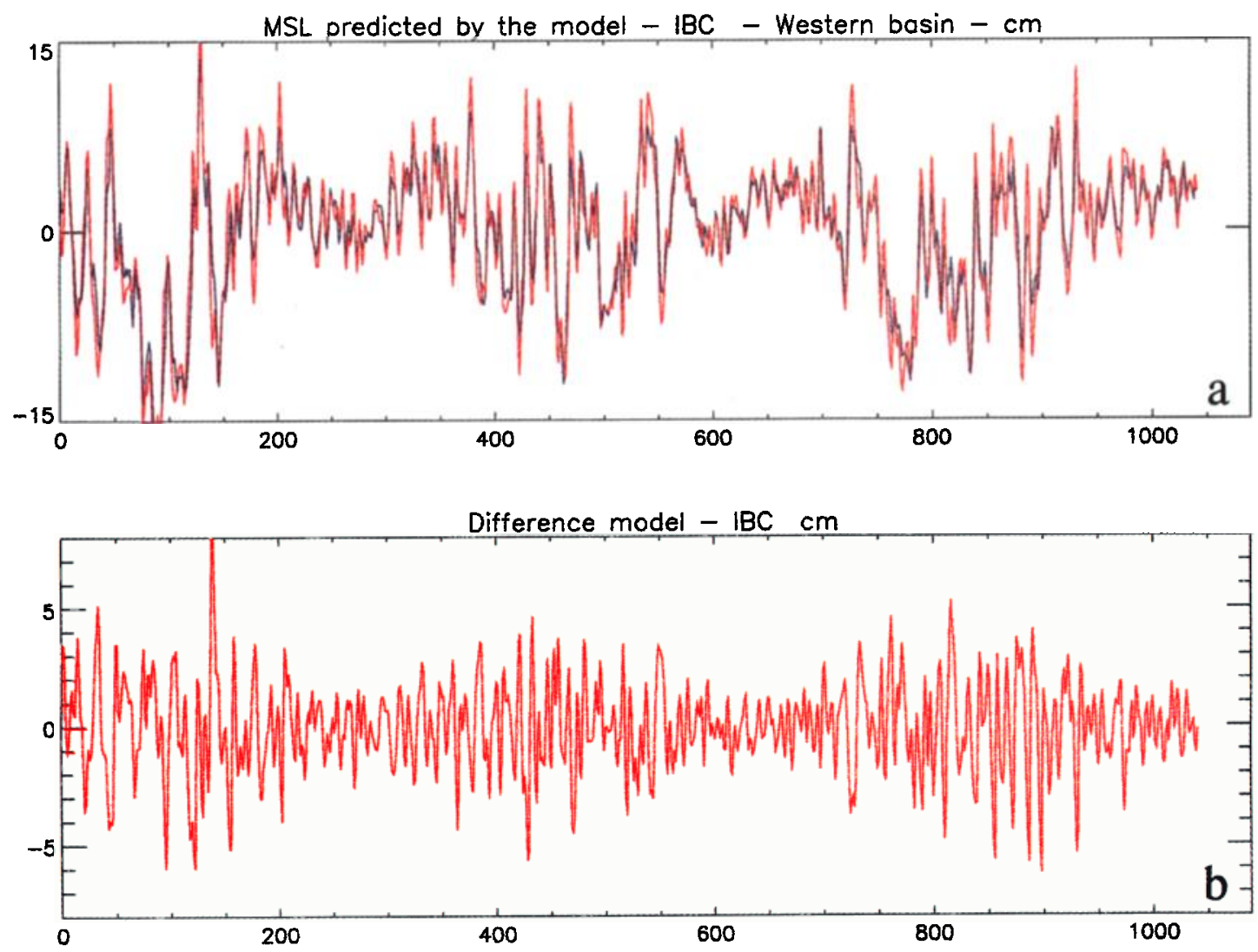

Plate 1. (a) Comparison between the sea level predicted by the model (blue line) and a standard inverse barometer correction (red line) for the western basin and (b) difference between the two corrections. The period is October 1992 to October 1995. Units are centimeters.
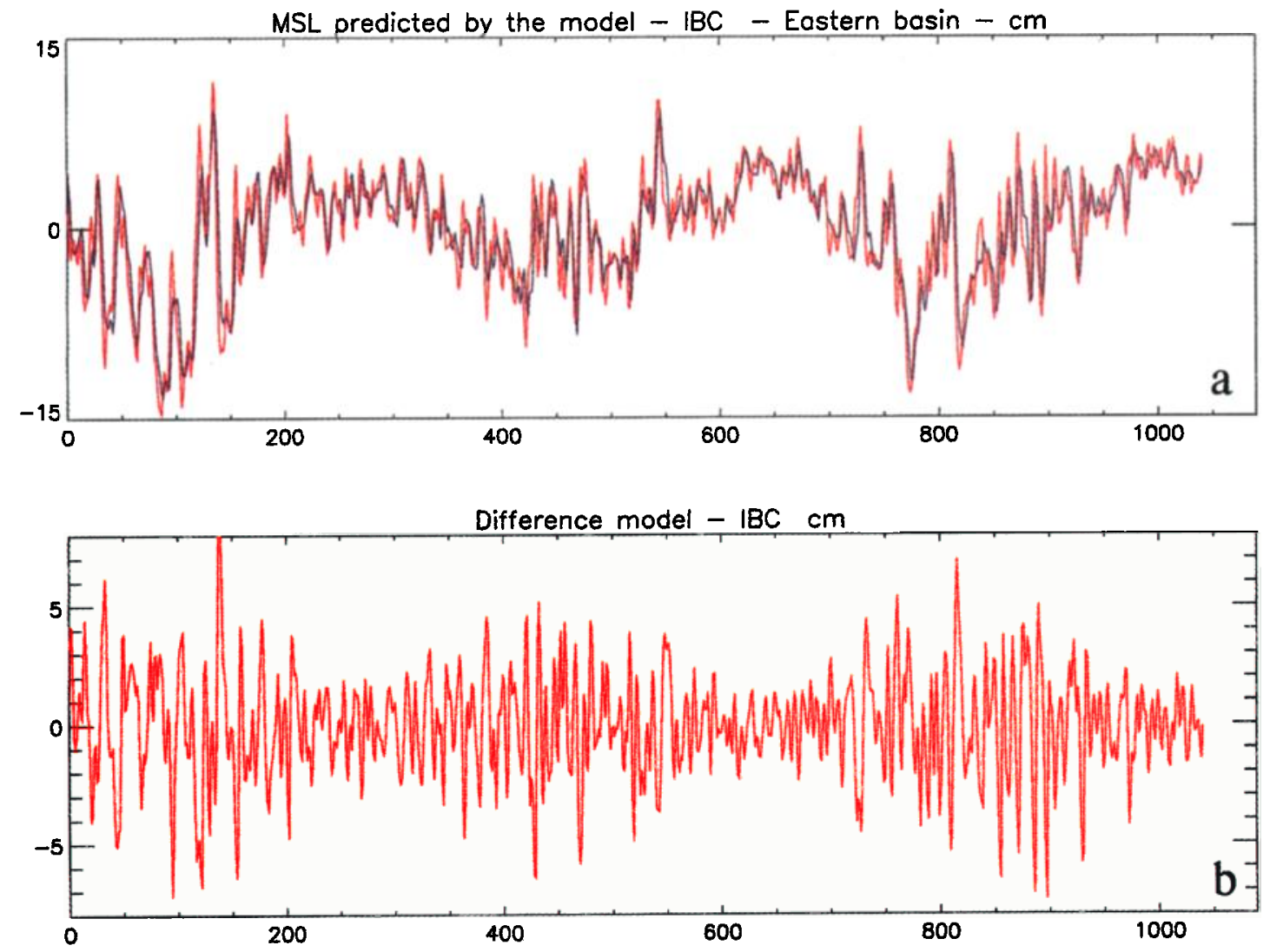

Plate 2. (a) Comparison of the sea level predicted by the model (blue line) and a standard inverse barometer correction (red line) for the eastern basin and (b) difference between the two corrections. The period is October 1992 to October 1995. Units are centimeters. 

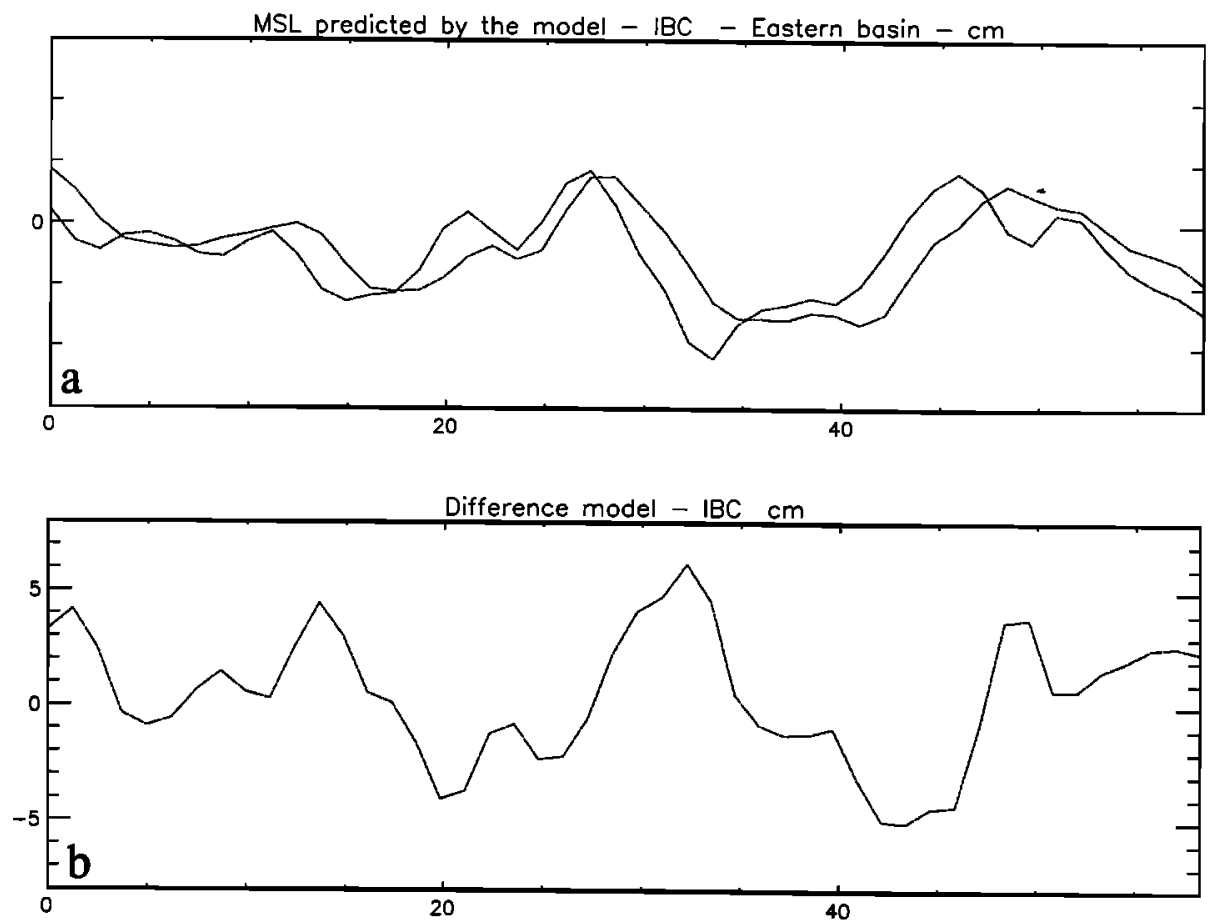

Figure 7. Same as Plate 2 but for the first 3 months only.

is the mean pressure over the basin) for the western basin. The temporal mean over the 3 years has been removed from the two time series. The differences between the two corrections are shown on Plate $1 b$. Plates $2 a$ and $2 b$ are for the eastern basin. The response given by the Candela model is slightly smoother and shows a phase delay. This is what we expect from the role of friction in the model. This is exemplified on Figures $7 \mathrm{a}$ and $7 \mathrm{~b}$, which correspond to Plates $2 \mathrm{a}$ and $2 \mathrm{~b}$ for the first 3 months of the time series.

Table 1 summarizes the comparison between the model and inverse barometer corrections. The rms difference between the two corrections is $1.9 \mathrm{~cm}$ (western basin) and $2.2 \mathrm{~cm}$ (eastern basin) with maximum differences of $\pm 8 \mathrm{~cm}$. The differences are larger during the winter, when atmospheric pressure has more high-frequency variations. The variance of the inverse barometer correction is $29 \mathrm{~cm}^{2}$ (western basin) and $20 \mathrm{~cm}^{2}$ (eastern basin). The response given by the Candela model is slightly less energetic. Its variance is $23 \mathrm{~cm}^{2}$ for the western basin and 17 $\mathrm{cm}^{2}$ for the eastern basin. Plates $3 \mathrm{a}$ and $3 \mathrm{~b}$ show the impact of

Table 1. Comparison of Candela Model Correction and Inverse Barometer Correction (IBC)

\begin{tabular}{lcc}
\hline & $\begin{array}{c}\text { Variance } \\
\text { Western Basin, } \\
\mathrm{cm}^{2}\end{array}$ & $\begin{array}{c}\text { Variance } \\
\text { Eastern Basin, } \\
\mathrm{cm}^{2}\end{array}$ \\
\hline T/P MSL & 82 & 82 \\
T/P MSL-IBC & 47 & 58 \\
T/P MSL-model & 42 & 51 \\
IBC & 29 & 20 \\
Model & 23 & 17 \\
IBC-model & 3.5 & 5 \\
\hline
\end{tabular}

The table shows the variance in T/P mean sea level (MSL) in the western and eastern basins, before and after correction by an IBC or the model. The variance of the two corrections and of their difference is also given. the Candela model correction on the $T / P$ mean sea level for the western and eastern basins, respectively. The variance of mean sea level before any correction for atmospheric pressure effect is about $82 \mathrm{~cm}^{2}$ for the two basins. The model explains a large part of the variance in T/P mean sea level variations $(50 \%$ for the western basin and $38 \%$ for the eastern basin). Compared to a standard inverse barometer effect, it explains an additional variance of $5 \mathrm{~cm}^{2}$ and $7 \mathrm{~cm}^{2}$ for the western and eastern basins, respectively. The model thus provides a better correction of atmospheric effect in T/P mean sea level. Given the difference between the two corrections $(2 \mathrm{~cm}$ rms with maximum differences of up to $\pm 8 \mathrm{~cm}$ ), the impact on mean sea level and oceanic circulation mapping is significant.

\subsection{Using the Model Correction to Map Sea Level Variations}

The model provides the sea level response to mean pressure over the western and eastern basins. Assuming a local adjustment to spatial variations in the pressure in the basin, we can derive the response of sea level to pressure $\operatorname{RP}(x, t)$ at any position $\mathrm{x}$ and time $t$ as

$$
\mathrm{RP}(\mathbf{x}, t)=\mathrm{CM}_{\langle P\rangle}(t)-1 / \rho g[P(\mathbf{x}, t)-\langle P\rangle(t)]
$$

$\mathrm{CM}_{\langle P\rangle}(t)$ is the response given by the Candela model, $\langle P\rangle(t)$ is the mean pressure over the western or eastern basin, and $P(\mathbf{x}, t)$ is the atmospheric pressure at position $\mathbf{x}$ and time $t$. Note that if $\mathrm{CM}_{\langle P\rangle}(t)$ is equal to a mean IBC $(-1 / \rho g\langle P\rangle)$, (5) yields a standard IBC.

We thus generated two sea level anomaly files for the 3 years of T/P data. The first one uses a standard IBC (as given by Lamicol et al. [1995]), the second one the correction RP given by (5). For this calculation the Candela model was forced using the nonfiltered atmospheric pressure time series (6 hours sampling) (filtered time series were previously used only for comparison with T/P mean sea level time series). 

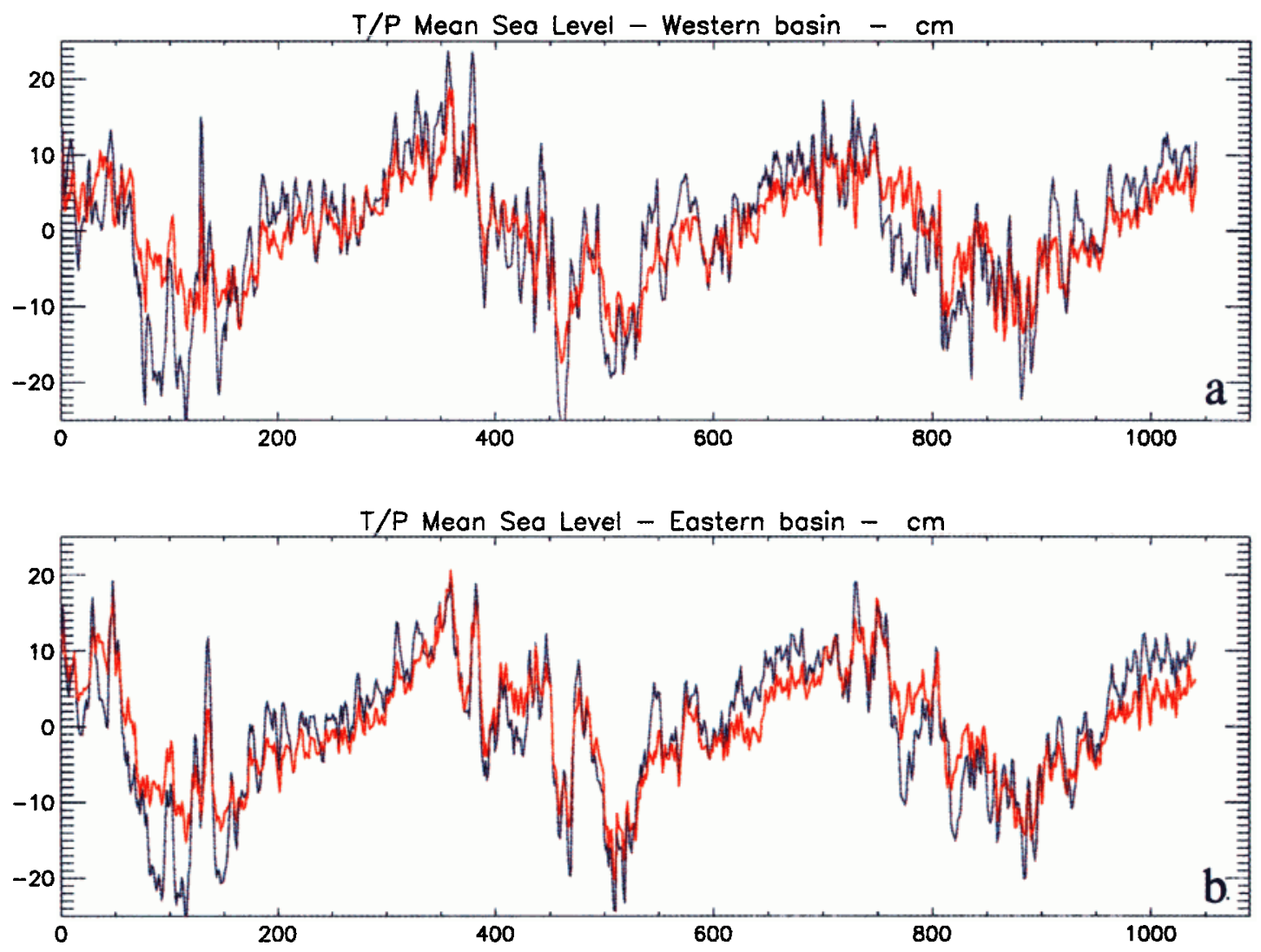

Plate 3. Impact of the Candela model correction on the T/P mean sea level for the (a) western and (b) eastern basins. The blue line corresponds to the T/P mean sea level without correction, and the red line corresponds to the T/P mean sea level with the Candela model correction. The period is October 1992 to October 1995. Units are centimeters.

The model results $\mathrm{CM}_{\langle P\rangle}$ with the nonfiltered atmospheric pressure time series are first summarized in Table 2. The difference between the IBC and the model now reaches $2.5 \mathrm{~cm}$ rms and $2.9 \mathrm{~cm}$ rms for the western and eastern basins, respectively. Compared to the results obtained with filtered time series of pressure (section 3.2), the variance of the IBC is increased by $5 \mathrm{~cm}^{2}$ (western basin) and $3 \mathrm{~cm}^{2}$ (eastern basin), while that of the model correction is increased only by $3 \mathrm{~cm}^{2}$ (western basin) and $1 \mathrm{~cm}^{2}$ (eastern basin). This is expected because the gain of the model response decreases according to frequency.

From the $\mathrm{CM}_{\langle P\rangle}$ correction the RP correction was then calculated and the two SLA files were compared. Shown on Figure 8 is the SLA variance for the two corrections (IB and RP) and the difference in variance as a function of cycle. Smoothing over three consecutive cycles was performed to reduce noise. The seasonal signal (which is identical for the two corrections) is the dominant signal seen in Figure 8. Figure 8 shows, in addition, that the variance obtained is almost always smaller with the RP correction than with the IB correction. The RP correction explains a mean additional variance of $6 \mathrm{~cm}^{2}$ in sea level variability, which is consistent with results given in section 4.3 . For some cycles it explains up to $20 \mathrm{~cm}^{2}$ more variance. This mainly occurs during winter seasons where atmospheric pressure can experience very rapid changes.

The impact on the mapping of sea level variation is illustrated by Plate 4 , which shows the sea level anomaly for cycles $17,18,19$, and 20 with the IB and RP corrections. With the
IBC, as already noted by Larnicol et al. [1995], a few tracks have large biases compared with neighboring tracks (e.g., cycle 18 ). These biases can have a large impact on the twodimensional mapping of sea level anomaly and oceanic circulation. These are well corrected for by the model. Note, however, that this is a case where the model explains a large part of additional variance compared to an IBC (see Figure 8). There are also some cycles for which the RP correction does no better than the IBC in reducing the along-track biases. These biases might be due to errors not related to atmospheric pressure (e.g., orbit or tidal errors) but more likely indicate limitations of the Candela model. This model is only integral (i.e., it only gives the mean response) and has a simple representation of strait dynamics.

Table 2. Comparison of Variance of Inverse Barometer Correction and Candela Model Correction and of Their Difference for Unfiltered Atmospheric Pressure Forcing

\begin{tabular}{lcc}
\hline & $\begin{array}{c}\text { Variance } \\
\text { Western Basin, } \\
\mathrm{cm}^{2}\end{array}$ & $\begin{array}{c}\text { Variance } \\
\text { Eastern Basin, } \\
\mathrm{cm}^{2}\end{array}$ \\
\hline IBC & 34 & 22 \\
Model & 26 & 18 \\
IBC-model & 6.5 & 8.5 \\
\hline
\end{tabular}



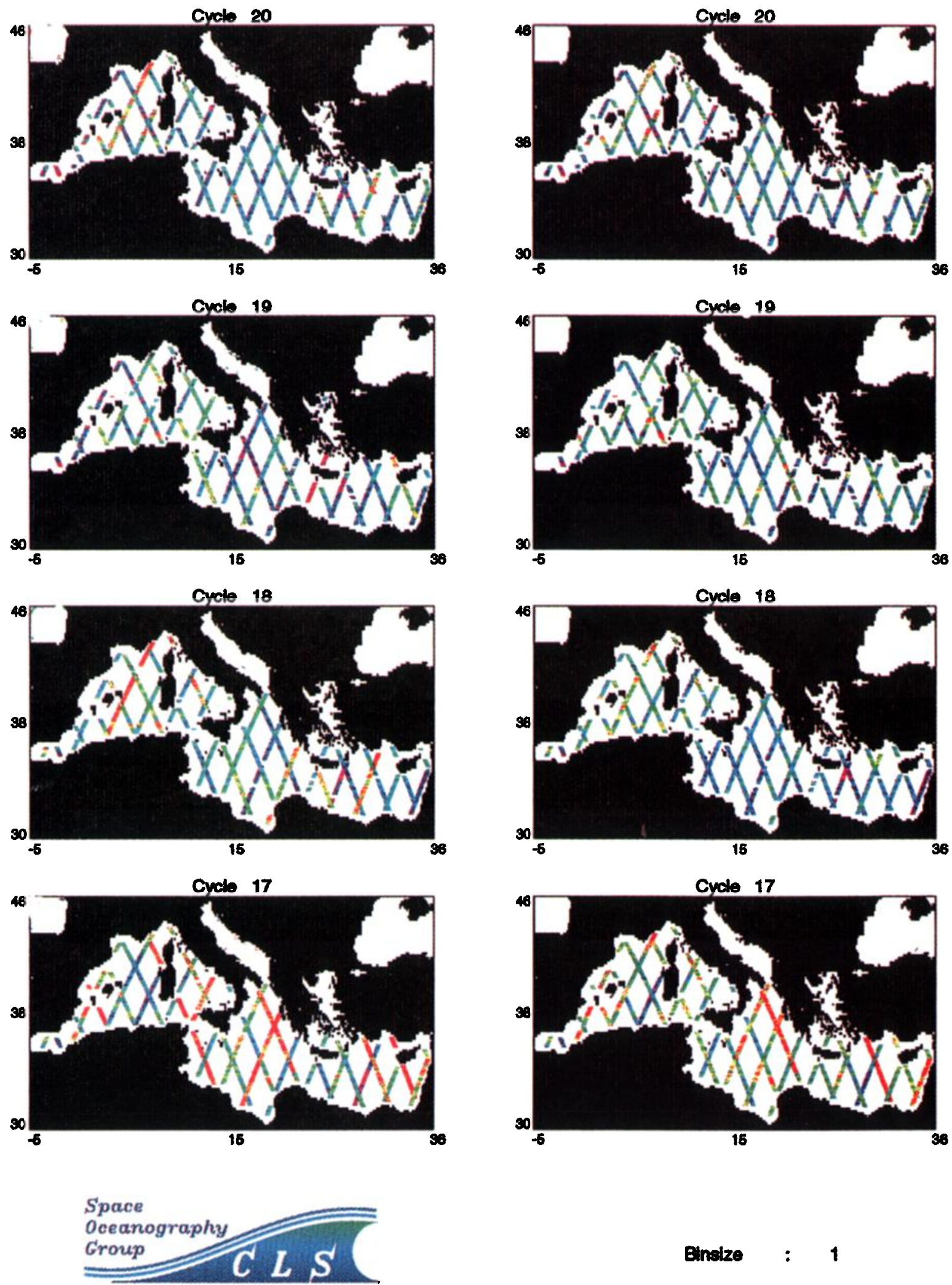

Binsize : 1

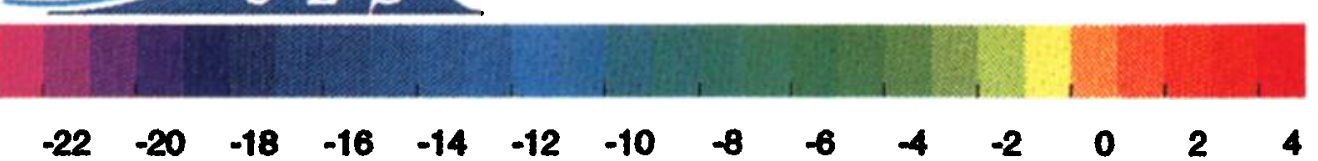

Plate 4. Along-track sea level anomaly for $\mathbf{T} / \mathbf{P}$ cycles $17,18,19$, and 20 using (left) a standard inverse barometer correction and (right) the Candela model correction. Units are centimeters. 

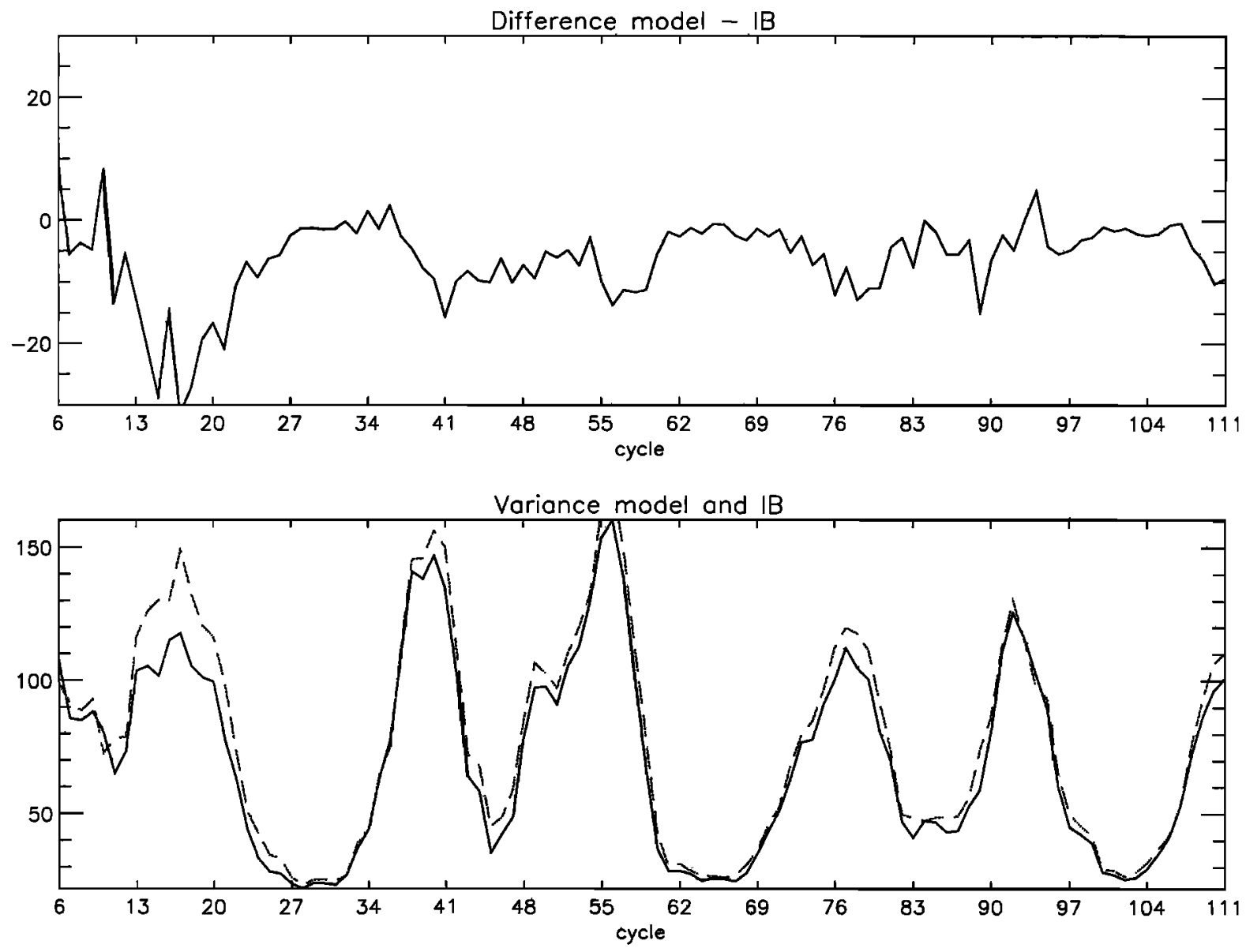

Figure 8. Variance of sea level anomaly for the inverse barometer (dashed line) and model (solid line) corrections and difference in variance according to cycle. Units are square centimeters.

\subsection{Role of Atmospheric Pressure Forcing} in the Atlantic

Until now the role of atmospheric pressure forcing in the Atlantic has been neglected. As previously mentioned, this assumes that the Atlantic sea level is free to respond isostatically to atmospheric pressure changes. The coherence analysis shown on Figure 5 implies a response close to a standard inverse barometer effect for frequencies lower than (6 days) ${ }^{-1}$. The small departures already observed are, however, likely to become larger at higher frequencies. According to the Candela model (equation (3)), this will induce a forcing function at the Strait of Gibraltar.

To take account of Atlantic pressure forcing at Gibraltar, we need to determine the value of $P_{0}$ the mean subsurface pressure in the Atlantic $\left(P_{0}=P_{a A}+\rho g \eta_{0}\right.$, where $P_{a \dot{A}}$ is the mean atmospheric pressure in the Atlantic box). Since $T / P$ measures $\eta_{0}$, we could directly estimate $P_{0}$. However, we need to separate the atmospheric component in the $\eta_{0}$ measured by $\mathrm{T} / \mathrm{P}$. We may assume that the atmospheric pressure signal dominates at high frequencies. A high-pass filter was thus applied to remove the nonatmospheric pressure driven variability. This, of course, also removes the low-frequency atmospheric pressure signal. However, the response at low frequencies is very close to an inverse barometer effect and thus does not induce a significant $P_{0}$. Several tests were performed with different cutoff frequencies ranging from (50 days) $)^{-1}$ to (5 days $^{-1}$. The variance explained in $T / P$ mean sea level was close to, but less than, that obtained without taking $P_{0}$ into account. This may be due to the influence of remaining nonatmospheric pressure signals in T/P data. $P_{0}$ should also correspond to the subsurface pressure just west of the strait which is not accessible from altimetry with the required time resolution (1.25 days).

Note, however, that even if we assume an inverse barometer effect in the Atlantic box, the influence of the Atlantic pressure on the Mediterranean mean sea level will not be completely negligible. Indeed, from (1), $P_{0}$ is actually equal to the reference pressure $P_{\text {ref }}$. Only a constant reference pressure will have no impact. In practice a time-varying mean pressure globally or over the Atlantic Ocean should be used.

\section{Conclusions}

The study demonstrates that compared to a standard inverse barometer correction, the simple analytical model proposed by Candela [1991] provides an improved correction of atmospheric pressure effects in TOPEX/POSEIDON data. The role of friction at the Strait of Gibraltar in limiting the exchange at high frequencies is well evidenced, while the role of friction at the Strait of Sicily is less clear. The correction obtained by the Candela model is smoother and shows a phase delay due to friction. It is thus less energetic, but it explains more variance in T/P mean sea level. As there is an rms difference of $2-3 \mathrm{~cm}$ between the two corrections, with maximum differences of up 
to $10 \mathrm{~cm}$, the impact on the mapping of oceanic circulation is not negligible.

In the future, improved corrections should be best derived, however, using numerical models [e.g., Candela and Lozano, 1994]. The models should take into account the complex bathymetry of the Mediterranean basin and the role of the Atlantic Ocean. However, the key issue should be to have a good representation of the dynamics in the Strait of Gibraltar. The role of internal hydraulic control [e.g., Bryden and Kinder, 1991] should, in particular, be addressed. Altimetric signals could also be directly assimilated in such models to correct certain model deficiencies and/or adjust certain model parameters (e.g., friction coefficient).

Acknowledgments. We thank A. Ganachaud who provided us with his coherence analysis tools. Atmospheric pressure observations were kindly processed by $\mathrm{H}$. Roquet from the AVISO Vent/Flux team at Meteo France. ECMWF data were also kindly provided by MeteoFrance. We acknowledge useful comments from P. Gaspar and R. Ponte. The study was partly funded as part of the European MAST MATER program and by SHOM under contract CLS/SHOM 95.87.026.00.470.29.045.

\section{References}

Archiving, Validation, and Interpretation of Satellite Data in Oceanography (AVISO), AVISO User Handbook: Merged TOPEX/ POSEIDON products, Rep. AVI-NT-02-101-CN, 2nd ed., Cent. Natl. d'Etudes Spatiales, Toulouse, France, 1992.

Bendat, J. S., and A. G. Piersol, Random Data. Analysis and Measurement Procedures, 2nd ed., 566 pp., John Wiley, New York, 1986.

Bryden, H. L., and T. H. Kinder, Steady two-layer exchange through the straits of Gibraltar, Deep Sea Res., Part A, 38, 445-463, 1991.

Candela, J., The Gibraltar Straits and its role in the dynamics of the Mediterranean Sea, Dyn. Atmos. Oceans, 15, 267-300, 1991.

Candela, J., and C. L. Lozano, Barotropic response of the western Mediterranean to observed atmospheric pressure forcing, in Seasonal and Interannual Variability of the Westem Mediterranean Sea, Coastal Estuarine Stud., vol. 46, edited by P. E. La Violette, pp. 325-359, AGU, Washington, D. C., 1994.

Candela, J., C. D. Winant, and H. Bryden, Meteorological forced subinertial flows through the straits of Gibraltar, J. Geophys. Res., 94, $12,667-12,679,1989$.
Cartwright, D. E., and R. J. Tayler, New computations of the tidegenerating potential, Geophys. J. R. Astron. Soc., 33, 253-264, 1971.

Crepon, M., Influence de la pression atmosphérique sur le niveau moyen de la Méditerranée Occidentale et sur le flux a travers le détroit de Gibraltar, Cah. Oceanogr., 1, 15-32, 1965.

Fu, L. L., and G. Pihos, Determining sea level's response to atmospheric pressure forcing using TOPEX/POSEIDON data, $J$. Geophys. Res., 99, 24,633-24,642, 1994.

Garrett, C., Variable sea level and strait flows in the Mediterranean: A theoretical study of the response to meteorological forcing, Oceanol. Acta, 6, 79-87, 1983.

Garrett, C., and F. Majaess, Noisostatic response of sea level to atmospheric pressure in the eastern Mediterranean, J. Phys. Oceanogr., 14, 656-665, 1984.

Gaspar, P., and R. M. Ponte, Relation between sea level and barometric pressure determined from altimeter data and model simulations, J. Geophys. Res., in press, 1997.

Gaspar, P., F. Ogor, P. Y. Le Traon, and O. Z. Zanife, Joint estimation of the TOPEX and POSEIDON sea-state biases, J. Geophys. Res., 99, 24,981-24,994, 1994.

Lacombe, H., Contribution à l'étude du détroit de Gibraltar, étude dynamique, Cah. Océanogr., 12, 73-107, 1961.

Larnicol, G., P. Y. Le Traon, N. Ayoub, and P. De Mey, Sea level variability in the Mediterranean Sea from 2 years of TOPEX/ POSEIDON data, J. Geophys. Res., 100, 25,163-25,177, 1995.

Lascaratos, A., and M. Gacic, Low frequency sea level variability in the northeastern Mediterranean, J. Phys. Oceanogr., 20, 522-533, 1990.

Le Traon, P. Y., J. Stum, J. Dorandeu, P. Gaspar, and P. Vincent, Global statistical analysis of TOPEX and POSEIDON data, J. Geophys. Res., 99, 24,619-24,631, 1994.

Ponte, R. M., Variability in a homogeneous ocean model forced by barometric pressure, Dyn. Atmos. Oceans, 18, 209-234, 1993.

Ray, R. D., and B. V. Sanchez, Radial deformation of the Earth by oceanic tidal loading, NASA Tech. Memo. 100743, 1989.

Tsimplis, M. N., and G. N. Vlahakis, Meteorological forcing and sea level variability in the Aegean Sea, J. Geophys. Res., 99, 9879-9890, 1994.

Wunsch, C., Bermuda sea level in relation to tides, weather and baroclinic fluctuations, Rev. Geophys., 10, 1-50, 1972.

P. Gauzelin and P.-Y. Le Traon, Direction Océanographie Spatiales, Collecte Localisation Satellites, 18 Avenue Edouard Belin, 31055 Toulouse Cedex, France. (e-mail: letraon@metis.cnes.fr)

(Received March 29, 1996; revised August 5, 1996; accepted September 6, 1996.) 